\title{
HEAVY OIL PRODUCTION WITH ENERGY EFFECTIVE STEAM-ASSISTED GRAVITY DRAINAGE
}

\author{
M. JONSKÅS HØHRBYE ${ }^{1}$, V. MATHIESEN ${ }^{2}$ \& B.M.E. MOLDESTAD ${ }^{1}$ \\ ${ }^{1}$ University College of Southeast Norway. \\ ${ }^{2}$ InflowControl AS.
}

\begin{abstract}
In reservoirs with extra heavy oil and bitumen, thermal methods are used to reduce the viscosity, in order to extract the oil. Steam-assisted gravity drainage (SAGD) is a thermal method where continuous steam injection is used. In this method, two horizontal wells are placed in parallel. The upper well injects steam and the lower well produces oil and condensed water. The continuous steam injection creates a chamber with uniform temperature. Heavy oil and bitumen reserves in Western Canada, which exceed 175 billion barrels, are becoming increasingly important petroleum sources due to the technical success of the SAGD processes. This study includes Computational fluid dynamics (CFD) modelling and simulations of a horizontal oil well with SAGD. The simulations are performed with inflow control devices (ICD) and autonomous inflow control valves (AICV) completion. In the SAGD processes, it is important that the residence time for steam in the reservoir is high enough to ensure that all the injected steam condenses in the reservoir to reduce the amount of steam injection and thereby making the SAGD process more energy effective. The simulations are carried out with ICD completion to delay the steam breakthrough and with AICV completion to prevent breakthrough of steam and water to the well. The numerical results showed that a most of the steam was produced together with the oil when ICD completion was used. AICV was able to close for steam and water, and the steam was thereby forced to condense in the reservoir, resulting in better utilization of the condensation energy.
\end{abstract}

Keywords: CFD, energy effective, extra heavy oil and bitumen, inflow control devices, SAGD.

\section{INTRODUCTION}

In reservoirs with extra heavy oil and bitumen, thermal methods are used to reduce the viscosity, in order to obtain enhanced oil recovery (EOR). Steam-assisted gravity drainage (SAGD) is a thermal method where steam injection is used. This method was invented by Butler in 1982 , and is now becoming one of the mature commercial technologies $[1,2]$.

Heavy oil and bitumen reserves in Western Canada, which exceed 175 billion barrels, are becoming increasingly important petroleum sources due to the technical success of the SAGD processes. In Alberta South West in Canada, SAGD processes are used by more than ten operators in the Athabasca and Cold Lake reservoirs. The oil viscosity in the Athabasca reservoirs is usually higher than $10^{6} \mathrm{cP}$, which implies that the oil is immobile and will not be affected by gravity drainage. To reduce the oil viscosity, most reservoirs in Alberta use the SAGD where the oil is heated to temperatures above of $200^{\circ} \mathrm{C}$. The oil viscosity is reduced to $10-20 \mathrm{cP}$ and the oil is then able to flow by gravity to the production well [2,3]. The SAGD process yields high efficiency for heavy oil and bitumen production, and the potential for EOR is significant and can be further improved. Between 2 and 5 tons of steam is injected per ton of bitumen produced [2]. SAGD economics are largely driven by the ratio of steam injection to oil production (SOR), and it is crucial to develop technology to decrease the SOR. Reducing the steam demand will not only have economic benefits, but it will also have a positive effect on the environment.

The SAGD process uses two parallel horizontal wells, as shown in Fig. 1. Steam is injected through the upper well, and is drained towards the lower oil production well. A continuous injection of steam through the upper well creates a chamber with uniform temperature equal 


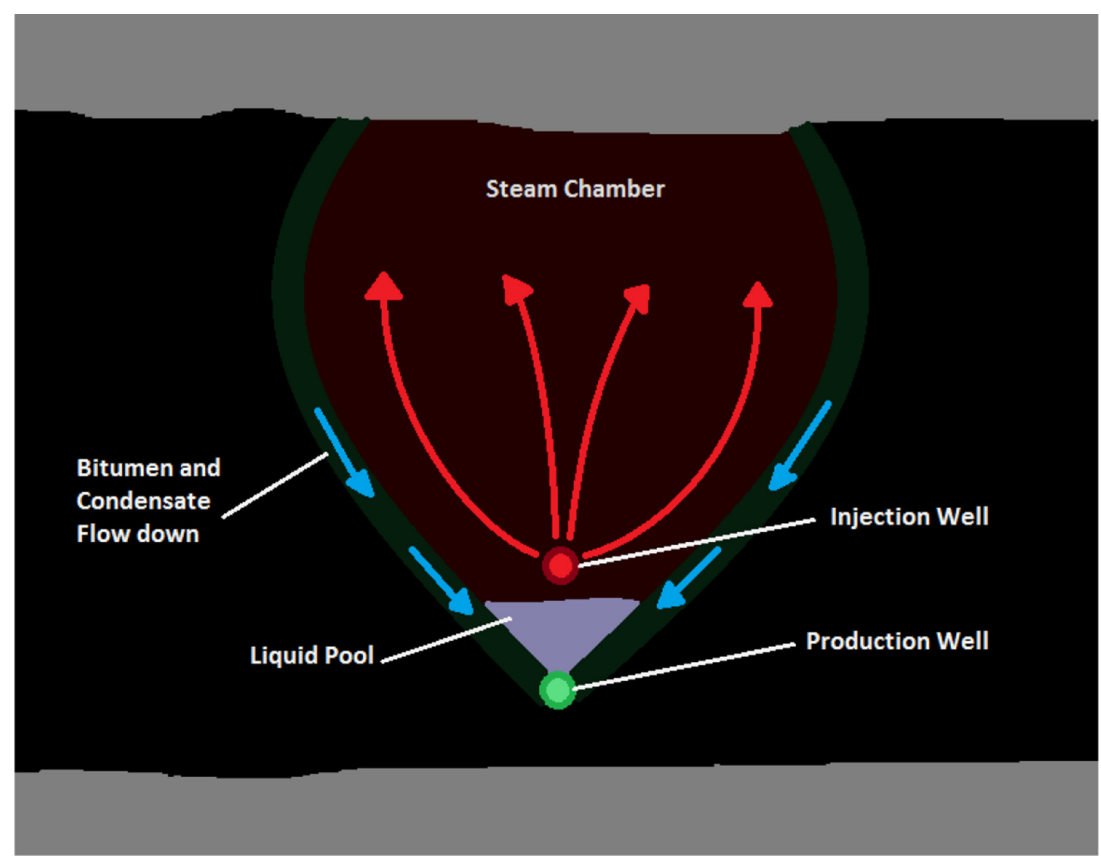

Figure 1: SAGD Process.

to the temperature of injected steam. In this chamber, which is called the depletion chamber, steam flows from the injection well to the immobile oil sand at the interface where latent steam energy is released. The release of energy as a result of steam condensation, leads to a higher temperature and mobility of heavy oil and bitumen, which then drains along the chamber edges and down to the production well. As the production of oil proceeds, the chamber grows upwards and to the sides [1-4].

This study includes 2-Dimensional (2D) CFD modelling and simulations of a horizontal oil well with SAGD. When SAGD is used for EOR, water and steam may be produced together with the oil after a while. If the residence time for steam in the reservoir is long enough, the steam will condense and only water will be produced together with oil. Still production of large amounts of water may lead to limitations in the separation system, and the volume flow has to be choked. This again will result in lower oil production.

The aim of this paper is to show the importance of using inflow control devices (ICD) to ensure that the condensation of steam occurs in the reservoir and thereby minimize the quantity of steam injected to the reservoir, decrease the SOR and improve the SAGD economics.

\subsection{Inflow technology}

Two different types of inflow control technology, ICD and autonomous inflow control valve (AICV), are used in the simulations to study the effect of delaying or preventing steam and water breakthrough to the production well. Different types of passive ICDs are developed to delay the early breakthrough by restricting the flow. In this project standard nozzle ICD is studied. Well completion with ICDs includes a large number of ICDs equally distributed along the well. The diameter of each nozzle is chosen to obtain the desired pressure drop over the ICD at a specific flow rate. The pressure drop highly depends on the nozzle 
diameter and the density of the fluid and less on the viscosity. ICDs are capable of delaying steam breakthrough significantly $[2,5]$. The newer technology, AICV, has the ability to close almost completely for steam and water. The valves will locally shut off the zones with steam and water breakthrough, and simultaneously produce oil from the other zones along the well. AICV can be designed to close for only steam or for both steam and water. The technology eliminates steam and water breakthrough problems, and removes the risk, cost and requirement for separation, transportation and handling of unwanted fluids. The technology is described by Aakre et al. [6-8]. Near well simulations with OLGA-Rocx has shown the potential of increased oil recovery with AICV completion [6]. In this study Ansys/Fluent is used to simulate the effect of SAGD in combination with ICD and AICV completion.

\section{COMPUTATIONAL SET-UP}

The aim of this study is to predict the flow behaviour in the reservoir and the flow rates through the production well when SAGD is used in combination with different inflow control technologies. The production well under consideration is 110 meters and the total length of the well is set to 800 meters. A principle drawing of the geometry and location of the steam injector and the production well is shown in Fig. 2.

In the simulations, ICD and AICV are used to control the inflow to the production well. Description of the restrictions is presented in Table 1.

$\Delta \mathrm{p}$ is the pressure drop over the ICDs and AICVs. The mesh used in the simulations is shown in Fig. 3. Different permeability zones are defined in order to simulate a heterogeneous reservoir. The horizontal and vertical permeability are specified for each zone and the values are presented in Table 2 and the location of the different zones is presented in Fig. 4. To be able to simulate a heterogeneous reservoir, the reservoir is divided into 5 zones.

The mesh contains 3,300 cells and the dimensions of the cells are $1 \times 0.200 \mathrm{~m}$ in the reservoir zone, $1 \times 0.038 \mathrm{~m}$ in the annulus and $1 \times 0.032 \mathrm{~m}$ in the producer. The inlets to

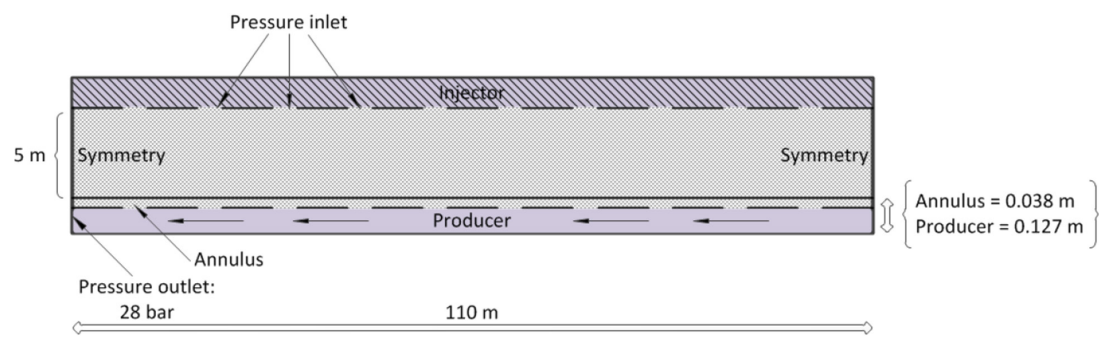

Figure 2: Principle drawing of the simulation set-up.

Table 1: Restrictions used for AICV®.

\begin{tabular}{llll}
\hline & Oil & Water & Steam \\
\hline ICD & $-\Delta \mathrm{p}=\frac{1}{2} \cdot \rho_{\text {oil }} \cdot|\mathrm{v}|_{2}^{2}$ & $-\Delta \mathrm{p}=\frac{1}{2} \cdot \rho_{\text {water }} \cdot|\mathrm{v}|_{2}^{2}$ & $-\Delta \mathrm{p}=\frac{1}{2} \cdot \rho_{\text {steam }} \cdot|\mathrm{v}|_{2}^{2}$ \\
AICV & $-\Delta \mathrm{p}=\frac{1}{2} \cdot \rho_{\text {oil }} \cdot|\mathrm{v}|_{2}^{2}$ & $|\mathrm{v}|_{2}=0$ & $|\mathrm{v}|_{2}=0$ \\
& & \\
\hline
\end{tabular}




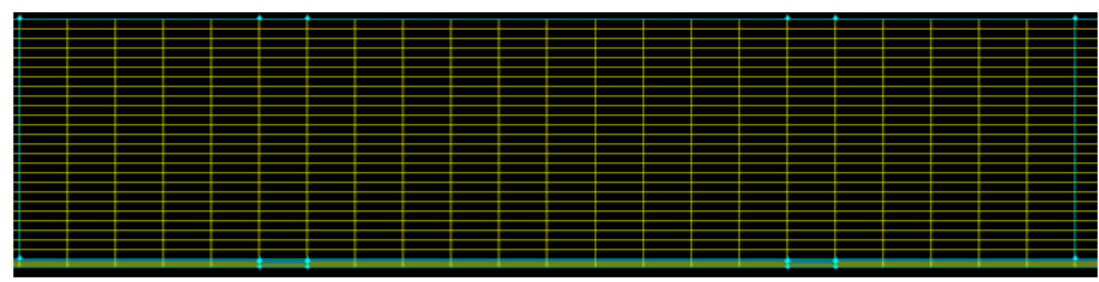

Figure 3: Enlarged view of a porous fluid zone.

Table 2: Permeability values used for the different zones.

\begin{tabular}{lll}
\hline & Property & Value $[\mathrm{mDa}]$ \\
\hline Horizontal perme- & Permeability for zone 1, 3 and 5 & 4,000 \\
ability & Permeability for zone 2 and 4 & 4,000 \\
& Permeability for the annulus & 20,000 \\
Vertical permeability & Permeability for zone 1, 3 and 5 & 1,000 \\
& Permeability for zone 2 and 4 & 3,000 \\
& Permeability for the annulus & 20,000 \\
\hline
\end{tabular}

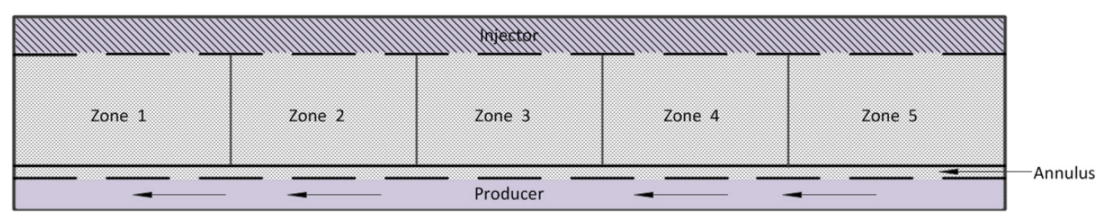

Figure 4: Different permeability zones in the reservoir.

the producer are $1 \mathrm{~m}$ and the valve diameters for the injector are represented by 10 pressure inlets of $1 \mathrm{~m}$ each. The main task is to study the effect of different flow restrictions, which is independent of the size of the valve openings.

The simulations are performed on the same bitumen reservoir. The properties are summarized in Table 3. The values used for the oil viscosity as a function of temperature [9] is shown in Fig. 5, and the function is included in ANSYS/Fluent.

The temperature boundary conditions for the injector and the producer outlet are $234^{\circ} \mathrm{C}$ and $214^{\circ} \mathrm{C}$ respectively. The pressures for the injector boundaries are calculated based on the pressure drop along a conventional injection well, i.e. based on the total length, diameter and total mass flow of steam in the injection well.

\section{RESULTS AND DISCUSSION}

The SAGD process is modelled using ANSYS/Fluent. The simulations have been performed by using the Eulerian two-dimensional multiphase model. The Eulerian multiphase model solves the momentum, energy and continuity equation for each phase. The coupling between the different phases is achieved through pressure and interface exchange coefficients and by using volume fractions of the phases $[10,11]$. Two different cases are presented here; one case is with ICD completion and one case with AICV completion. AICV is designed to close for steam and water. 
Table 3: Fluid and formation properties.

\begin{tabular}{|c|c|c|}
\hline & Property & Value \\
\hline \multirow[t]{4}{*}{ Density } & Oil density, $\rho_{\text {oil }}\left[\mathrm{kg} / \mathrm{m}^{3}\right]$ & 1,002 \\
\hline & Water density, $\rho_{\text {water }}\left[\mathrm{kg} / \mathrm{m}^{3}\right]$ & 827 \\
\hline & Steam density, $\rho_{\text {steam }}\left[\mathrm{kg} / \mathrm{m}^{3}\right]$ & 15 \\
\hline & Formation density, $\rho_{\text {formation }}\left[\mathrm{kg} / \mathrm{m}^{3}\right]$ & 2,370 \\
\hline \multirow[t]{4}{*}{ Specific heat } & Specific heat of oil, $\mathrm{C}_{\mathrm{p}, \mathrm{oil}}[\mathrm{J} / \mathrm{kg} \mathrm{K}]$ & 2,720 \\
\hline & Specific heat of water, $\mathrm{C}_{\mathrm{p} \text {,water }}[\mathrm{J} / \mathrm{kg} \mathrm{K}]$ & 4,678 \\
\hline & Specific heat of steam, $\mathrm{C}_{\mathrm{p} \text { steam }}[\mathrm{J} / \mathrm{kg} \mathrm{K}]$ & 3,381 \\
\hline & Specific heat of formation, $\mathrm{C}_{\mathrm{p} \text {,formation }}[\mathrm{J} / \mathrm{kg} \mathrm{K}]$ & 2,340 \\
\hline \multirow{4}{*}{$\begin{array}{l}\text { Thermal conduc- } \\
\text { tivity }\end{array}$} & - Thermal conductivity for oil, $\mathrm{k}_{\mathrm{oil}}[\mathrm{W} / \mathrm{mK}]$ & 0.131 \\
\hline & Thermal conductivity for water, $\mathrm{k}_{\text {water }}[\mathrm{W} / \mathrm{mK}]$ & 0.6 \\
\hline & Thermal conductivity for steam, $\mathrm{k}_{\text {steam }}[\mathrm{W} / \mathrm{mK}]$ & 0.016 \\
\hline & Thermal conductivity for the formation, $\mathrm{k}_{\text {formation }}[\mathrm{W} / \mathrm{mK}]$ & 2.7 \\
\hline \multirow[t]{3}{*}{ Viscosity } & Oil viscosity, $\mu_{\mathrm{oil}}[\mathrm{cP}]$ & See Fig. 5 \\
\hline & Water viscosity, $\mu_{\text {water }}[\mathrm{cP}]$ & 0.11578 \\
\hline & Steam viscosity $\mu_{\text {steam }}[\mathrm{cP}]$ & 0.0167785 \\
\hline Rock properties & Porosity[-] & 0.33 \\
\hline \multirow{3}{*}{$\begin{array}{l}\text { Other specifica- } \\
\text { tions }\end{array}$} & Temperature injector, $\mathrm{T}_{\text {injection }}\left[{ }^{\circ} \mathrm{C}\right]$ & 234 \\
\hline & Temperature for producer, $\mathrm{T}_{\text {producer }}\left[{ }^{\circ} \mathrm{C}\right]$ & 214 \\
\hline & Injected volume fraction of steam, $\mathrm{y}_{\text {steam }}[-]$ & 0.9999 \\
\hline
\end{tabular}

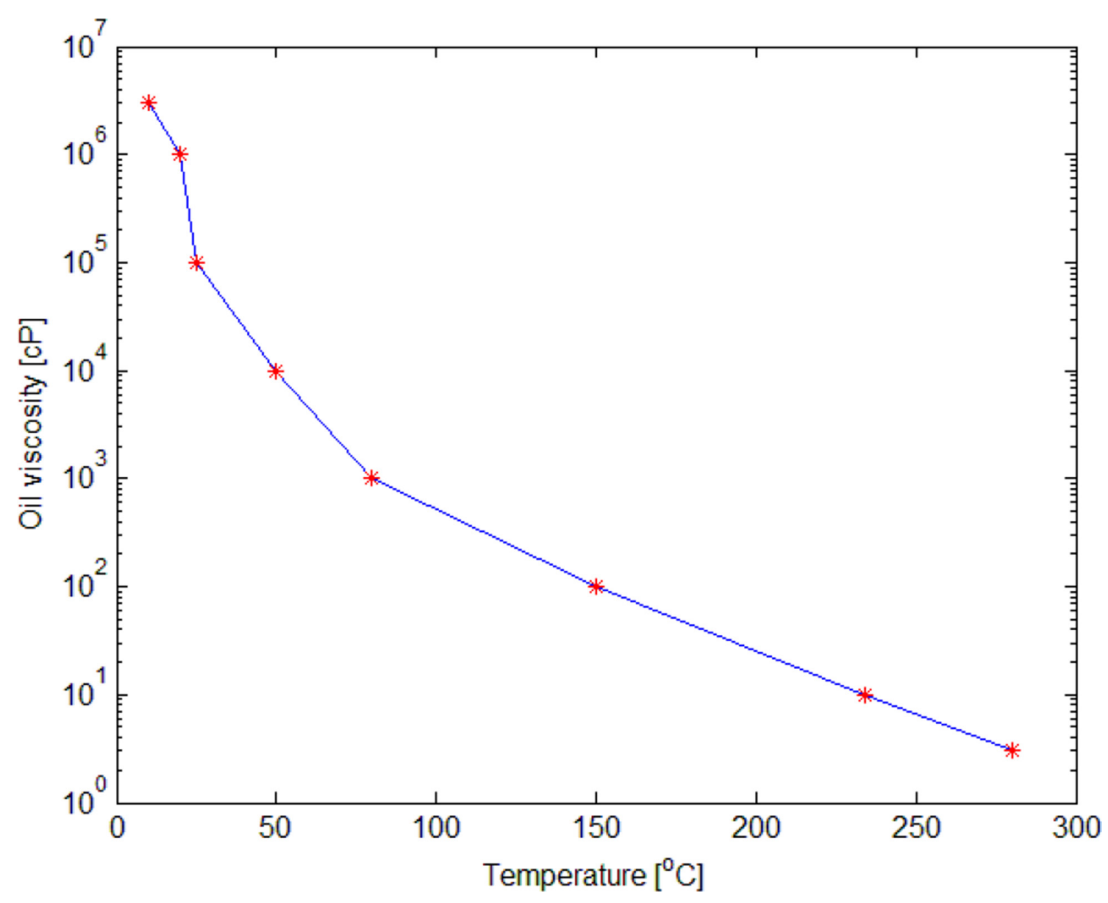

Figure 5: Oil viscosity as a function of temperature. 


\subsection{Simulation of oil production using ICD completion}

The ICDs are installed in order to delay the steam and water breakthrough to the producer. The oil, water and steam production are adjusted as described in Table 1 . The production rate is about constant at $14 \mathrm{~m}^{3} /$ day until the steam and water breakthrough occurs after 3.4 days. After breakthrough the production rate starts to fluctuate significantly and steady flow conditions were not obtained. The fluctuations may be due to numerical instabilities when large amounts of steam flow into the well and condensation of steam in the well occurs. It is important that the residence time for the steam in the reservoir is long enough to obtain condensation in the reservoir and thereby optimize the degree of heat transfer within the reservoir. When using ICD completion, the steam breakthrough is delayed, but when the breakthrough occurs the ICDs are not able to choke or stop the steam, and the steam production is becoming significantly higher than the oil production from the same location. The three-phase flow with steam, water and oil in the producer leads to instabilities in the flow.

Figure $6 \mathrm{a}$ and $\mathrm{b}$ show the volume fraction of oil (red) in the reservoir after 1 and 3 days of production respectively. The volume fraction of steam in the reservoir (red) after 3.5 days is presented in Fig. 7. Comparison of the volume fraction of steam and oil after about 3 days indicates that the oil has been replaced by steam and that very little steam is condensed in the reservoir. It can also be seen that in the region with high permeability, the steam reaches the producer much faster than in the low permeability zones. No water was observed in the reservoir, which indicates that the residence time in the reservoir is too short for the steam to condense, and the latent heat in the steam is thereby not utilized. Steam has still not reached the well in the low permeability zones after 3 days. The residence time in those zones may be high enough for some of the steam to condense.

\subsection{Simulation of oil production using AICV completion}

In this case the functionality of the AICV is to close for both steam and water. The disadvantage with closing totally for water can be a lower production rate of oil. However, the well will be capable of producing for a long period of time, and the total accumulated oil production is assumed to increase. In addition, the problems caused by multiphase flow in the pipeline will be avoided. Multiphase flow in pipelines will always be a challenge in oil production and can be solved by AICVs that have an autonomous phase filter effect. Figure 8 shows the oil production versus time. The production has been run for 11 days. The

a)

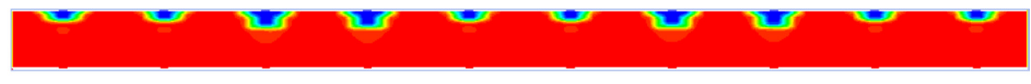

b)

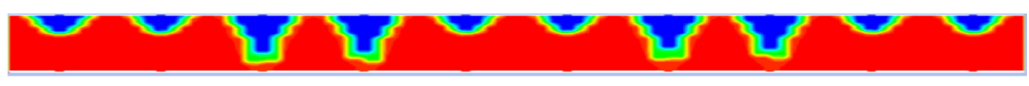

Figure 6: Volume fraction of oil in the reservoir for ICD. Production period: (a) 1 days, (b) 3 days. Red is $100 \%$ oil, blue is $0 \%$ oil.

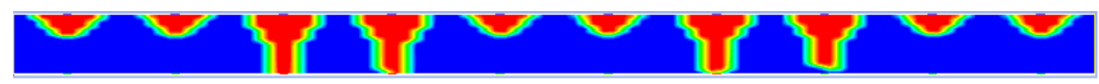

Figure 7: Volume fraction of steam in the reservoir for ICD. Production period: 3.5 days. Red is $100 \%$ steam, blue is $0 \%$ steam. 


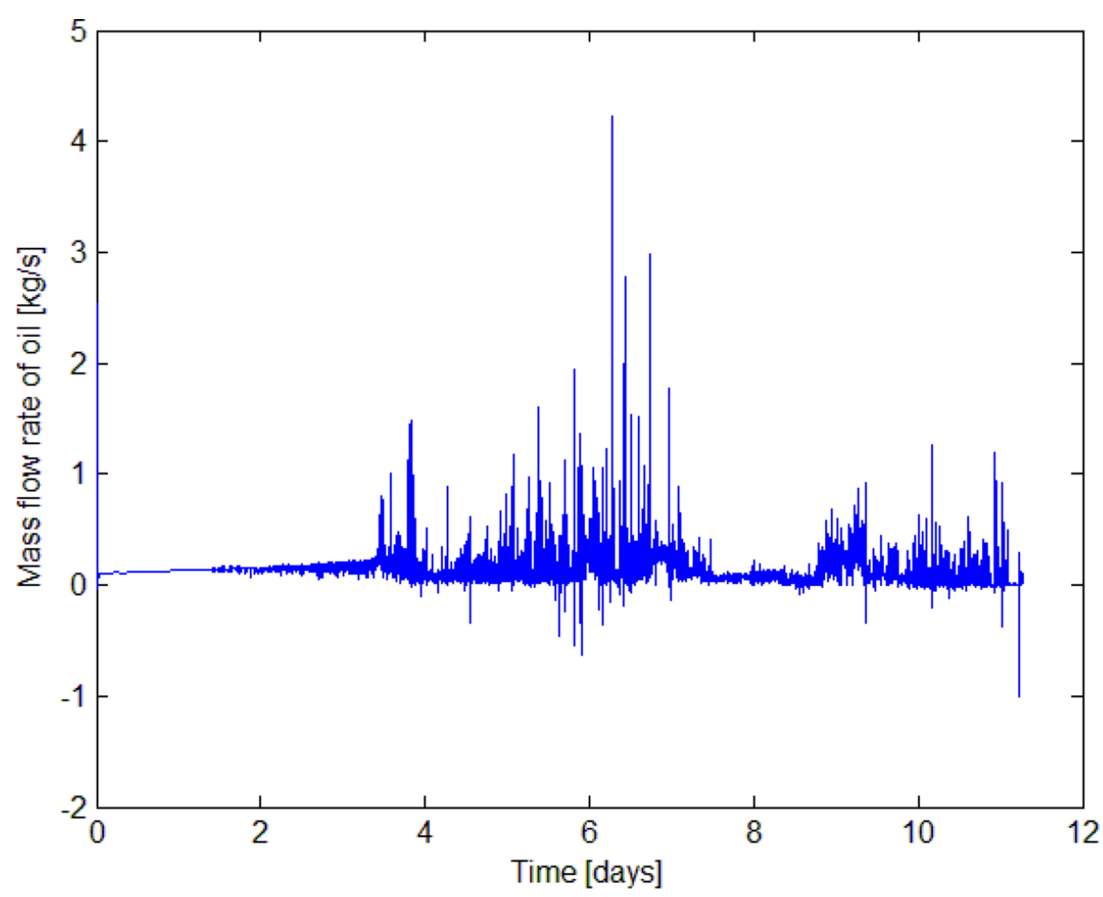

Figure 8: Mass flow rate of oil as a function of time. AICV designed to close for water and steam.

large fluctuations are most probably due numerical instabilities. The small variations may be due to the functionality of the AICV which includes closing for water and steam and open again when oil is surrounding the valve. The average mass flow rate of oil (based on 11 days of production) is $0.1061 \mathrm{~kg} / \mathrm{s}\left(\approx 9.1 \mathrm{~m}^{3} /\right.$ day $)$ which is significantly lower than in the previous case, but the total production over time will most probably be higher. Further simulations may be performed to show the accumulated oil production over a longer period with the different solutions. In this study it is important to ensure that the condensation of steam occurs in the reservoir to minimize the quantity of required steam injection to the reservoir.

Volume fraction of oil in the reservoir at different times is presented in Fig. 9 (red is 100\% oil, blue is $0 \%$ oil). After a few days, steam and water reaches the well in the more permeable zones, and the AICVs close. The AICVs are reversible and will open again if oil is surrounding the valves. As can be seen from the figure, the less permeable zones are still producing oil after 9 days.

Figure 10 shows the volume fraction of steam in the reservoir at different times (red is $100 \%$ steam, blue is $0 \%$ steam). As the steam reaches the well, the AICVs close and the steam is kept in the reservoir and condenses after a while. In this way, heat of condensation can be utilized to decrease the viscosity of the oil, and less steam has to be injected. This shows the potential of increased oil recovery from very heavy oil and bitumen reservoirs with SAGD in combination with new inflow control technology.

The volume fraction of the water with time is shown in Fig. 11 (red is $100 \%$ water and blue is $0 \%$ water). As can be seen, the water fraction in the most permeable zones increases 
a)

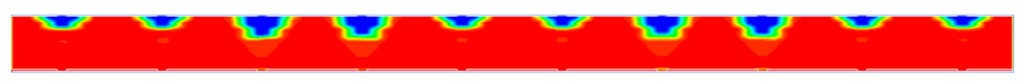

b)

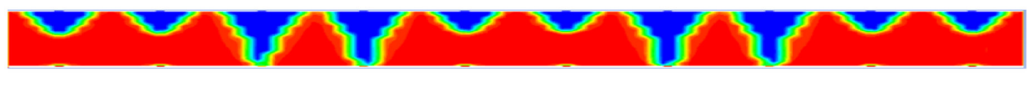

c)

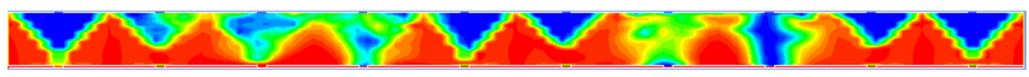

Figure 9: Volume fraction of oil in the reservoir, AICV. (a) 1.5 days, (b) 4 days, (c) 9 days. Red is $100 \%$ oil, blue is $0 \%$ oil.

a)

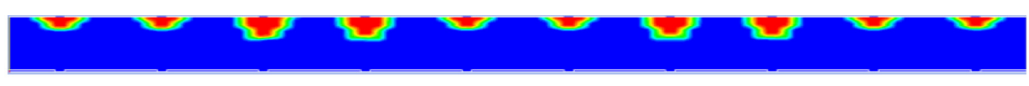

b)

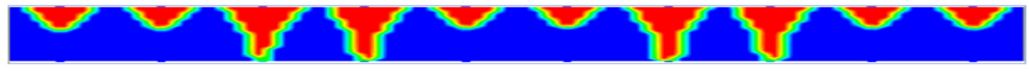

c)

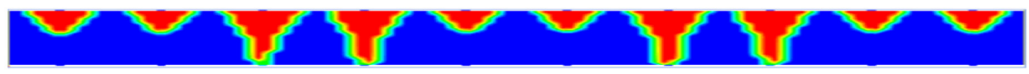

Figure 10: Volume fraction of steam in the reservoir, AICV. (a) 1.5 days, (b) 4 days, (c) 9 days. Red is $100 \%$ steam, blue is $0 \%$ steam.

a)

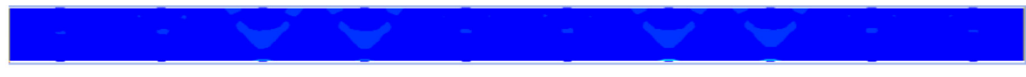

b)

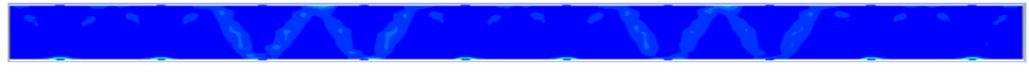

c)

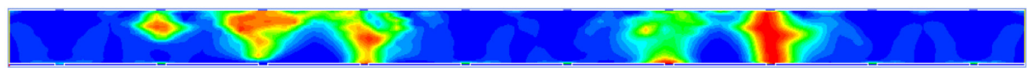

Figure 11: Volume fraction of water in the reservoir, AICV. (a) 1.5 days, (b) 4 days, (c) 9 days. Red is $100 \%$ water, blue is $0 \%$ water.

after the AICVs have closed for steam. This shows that the steam condenses and releases heat when the AICVs close. After 9 days, the concentration of water is close to $100 \%$ in one zone.

\subsection{Comparison of the results}

The results from the simulations with ICD and AICV completion show that in SAGD processes, inflow control is important to be able to utilize the latent heat in the injected steam and in that way reduce the quantity of steam injection. ICD can delay the breakthrough of steam and in that way increase the residence time of steam in the reservoir. However, when breakthrough occurs, the ICD is not able to choke or close for steam, and a lot of steam will be produced together with the oil. AICV can close for steam in the breakthrough zone, and in that way ensure that the heat of condensation is utilized in the reservoir. The valve will then open again when oil is surrounding the valve. The AICV design used in the simulation closed for both water and steam. The problem with multiphase flow in the well was thereby avoided. More simulations are needed to study the effect of increased oil recovery for the ICD and AICV cases. However, this study has 
shown that that wells with AICV completion has the potential to make the heavy oil production with SAGD more energy effective.

\section{CONCLUSION}

In reservoirs with heavy oil and bitumen thermal methods as SAGD have to be used to reduce the viscosity, increase the mobility of the oil and thereby obtain EOR. The SAGD process is modelled using ANSYS/Fluent. The simulations have been performed by using an Eulerian 2-D multiphase model which solves the mass, momentum and energy equations for each phase. The coupling between the different phases is achieved through pressure and interface exchange coefficients and by using volume fractions of the phases.

Two cases were simulated to study SAGD in combination with inflow control technologies. The well was completed with standard nozzle ICDs in the first case and with AICV the second case. ICD delays steam and water breakthrough and AICV can be designed to close for both steam and water. A $110 \mathrm{~m}$ long well section with 10 inflow controllers was considered. The total length of the well was assumed to be 800 meters. The average oil flow rates were $14 \mathrm{~m}^{3} /$ day and $9.1 \mathrm{~m}^{3}$ /day when using ICD and AICV respectively. However, the calculations are based on different periods of time, and more simulations are needed to compare the accumulated oil production over time and comparing the total oil recovery for the different cases.

Large quantities of steam are produced together with oil in the ICD case which indicates that a significant quantity of latent heat has not been utilized. Production of steam and water are prevented in the AICV case. When the AICVs close for steam in the breakthrough zones, the heat of condensation is utilized in the reservoir and the amount of steam injected per $\mathrm{m}^{3}$ of oil produced can be reduced significantly. Multiphase flow in pipelines has always been a challenge, and this problem can be reduced or solved with AICV completion. More simulations are needed to study the effect of increased oil recovery using ICD and AICV completion.

\section{REFERENCES}

[1] Barillas, J.L.M., Dutra Jr, T.V. \& Mata, W., Reservoir and operational parameters influence in SAGD process. Journal of Petroleum Science and Engineering, 54(1-2), pp. 34-42, 2006. http://dx.doi.org/10.1016/j.petrol.2006.07.008

[2] Gates, I.D. \& Leskiw, C., Impact of steam trap control on performance of steam-assisted gravity drainage. Journal of Petroleum Science and Engineering, 75(1-2), pp. 215-222, 2010. http://dx.doi.org/10.1016/j.petrol.2010.11.014

[3] Gotawala, D.R. \& Gates, I.D., Stability of the edge of a SAGD steam chamber in a bitumen reservoir. Chemical Engineering Science, 66(8), pp. 1802-1809, 2011. http://dx.doi.org/10.1016/j.ces.2011.01.025

[4] Bader, A.A., A surface-subsurface model for the techno-economic and risk evaluation of thermal EOR projects, in power and propulsion, Cranfield University, 2011.

[5] Al-Khelaiwi, F.T. \& Davies, D.R., Heriot-Watt University and Saudi Aramco, and Heriot-Watt University, Inflow Control Devices: Application and Value Quantification of a Developing Technology, International Oil Conference and Exhibition in Mexico, Veracruz, Mexico, 27-30 June, 2007.

[6] Aakre, H., Halvorsen, B.M., Werswick, B. \& Mathiesen, V., Smart well with autonomous inflow control valve technology. SPE 164348-MS, Middle East Oil and Gas Show and Exhibition, Manama, Bahrain, March 2013. 
[7] Aakre, H., Halvorsen, B.M., Werswick, B. \& Mathiesen, V., Increased oil recovery of an old well recompleted with Autonomous Inflow Control V (AICV), ADIPEC, November 10-13, 2013.

http://dx.doi.org/10.2118/171141-ms

[8] Aakre, H., Halvorsen, B., Werswick, B. \& Mathiesen, V., Autonomous inflow control valve for heavy and extra-heavy oil, Medellin, Colombia, 2014.

[9] Spirax sarco. 2012, available at: http://www.spiraxsarco.com/resources/steam-tables.asp.

[10] ANSYS FLUENT 12.0 Theory Guide. 2009. 535,571.

[11] ANSYS FLUENT 12.0 Theory Guide. 2009, ANSYS. p. 660,662. 